\title{
Anti-Biofilm and Antimicrobial Activities of Five Edible and Medicinal Macrofungi Samples on Some Biofilm Producing Multi Drug Resistant Enterococcus Strains
}

\author{
Başar Karaca $^{1, a}$, Arzu Çöleri Cihan ${ }^{1, b}$, Ilgaz Akata ${ }^{1, c}$, Ergin Murat Altuner ${ }^{2, d, *}$ \\ ${ }^{1}$ Department of Biology, Faculty of Science, Ankara University, 06100 Ankara, Turkey \\ ${ }^{2}$ Department of Biology, Faculty of Science and Arts, Kastamonu University, 37150 Kastamonu, Turkey
} *Corresponding author

A R T I C L E I N F O
Research Article

Received : 30/05/2019
Accepted : 29/11/2019

A B S T R A C T

It is commonly well-known that biofilms are the predominant mode of bacterial growth, reflected in the clinic observations, where approximately $80 \%$ of all bacterial infections are related to biofilms. Bacteria in biofilms are well protected against environmental stresses, antibiotics, disinfectants and the host's immune system and are usually extremely difficult to eradicate. Due to common problems caused by biofilms, alternative anti-biofilm strategies must be developed. Enterococcus strains are able to form complex surface-associated communities (biofilms), which contribute to its resistance and persistence in both host and non-host environments, and are especially important in food processing and clinical environments. Enterococcus biofilms showed increased antimicrobial resistance to the most of antibiotics as compared to the planktonic bacteria, which make them

Keywords:

Macrofungus difficult to combat. There is an increasing evidence that biofilms are often associated with infectious diseases. Novel anti-biofilm strategies must be designed to include natural bio products instead of Biofilm Enterococcus

Multi drug resistance Edible and Medicinal Macrofung common antibiotics. Mushrooms are a nutritionally functional foods and a source of pharmaceuticals having functions such as antitumor, immunomodulating, antioxidant, cardiovascular, antihypercholesterolemia, antiviral, antibacterial, anti-parasitic, antifungal, detoxification, hepatoprotective, and antidiabetic. In addition, they have a notable activity against biofilms. In this study, the antimicrobial and anti-biofilm activities of some medicinal and edible mushrooms, namely Morchella angusticeps Peck, Ganoderma lucidum (Curtis) P. Karst., Cerioporus squamosus (Huds.) Quél., Trametes versicolor (L.) Lloyd and Lentinula edodes (Berk.) Singer were screened against multi drug resistant Enterococcus strains. As a result, it was observed that these mushrooms have notable potency to develop alternative medicines to struggle infectious diseases and biofilms.

https://orcid.org/0000-0002-7289-6251 https://orcid.org/0000-0001-5351-8071

\section{Introduction}

The use of natural products to overcome antimicrobial resistance can be considered as an alternative approach (Altuner and Akata, 2010; Ogidi, 2015; Sevindik et al., 2018). In addition to their antimicrobial activities, some natural extracts are known to inhibit biofilm formation (Kim et al., 2008).

As a result of many scientific researchers conducted up to now, it has been determined that some macrofungi species have various chemical components showing antibacterial, antifungal, antiviral, antioxidant, anticancer, immunostimulant and antiprotozoal properties (Bentley, 1997; Altuner and Akata, 2010; Balde et al., 2010; Altuner et al., 2012a,b; Evidente et al., 2014; Canli et al., 2016; Hameed et al., 2017; Ogbole et al., 2018; Sevindik, 2018;
Sevindik, 2019). Macrofungi produce these chemical components for several purposes, such as to be used against the competitive species or to be able to survive in the environment in which they are distributed (Losada et al., 2009). Considering the fact that macrofungi have a wide range of biological activities, it is necessary to focus on isolation and standardization studies of active compounds, which can be an alternative to synthetic drugs (De Silva, 2013). Antibiotic therapies can reverse the symptoms of planktonic cells released from biofilms, but in most cases are ineffective in destroying biofilms (Roy et al., 2018). Despite repeated antibiotic therapy, it may be necessary to remove the biofilm from the body by surgical intervention (Blanchette and Wenke, 2018). In addition to a resistance 
against antibiotics, antibiotic therapies that are administered below the appropriate concentration may also contribute to the formation of biofilms. This phenomenon complicates the treatment of biofilm-related infections and may adversely affect the course of the disease due to incorrect dosing strategies (Lebeaux et al., 2014). In some cases, the insufficiency of widespread antimicrobial therapies against biofilms lead scientists to the discovery and identification of new antimicrobial agents (Buommino et al., 2014). Some macrofungi, which have antimicrobial activities also have a high potential for research in antibiofilm studies to develop specific approaches to combat biofilms (de Carvalho et al., 2015).

In this study, the antimicrobial and anti-biofilm activities of some medicinal and edible mushrooms, namely $M$. angusticeps, $G$. lucidum, $C$. squamosus, $T$. versicolor and $L$. edodes were screened against multi drug resistant Enterococcus strains.

\section{Materials and Methods}

\section{Macrofungi Samples and Extraction}

Five medicinal and edible macrofungi samples $M$. angusticeps, G. lucidum, C. squamosus, T. versicolor and L. edodes from Fungarium of Ankara University, which were previously collected, identified and food dehydrator dried by Dr. Ilgaz AKATA, were used in the study. In extraction of bioactive compounds, a method which was previously defined by Altuner et al (2014), was used with some modifications. $20 \mathrm{~g}$ of ground macrofungi samples were shaken in $200 \mathrm{~mL} 60 \%$ methanol at $30^{\circ} \mathrm{C}$ and 150 $\mathrm{rpm} / \mathrm{min}$ for 24 hours. After extraction process, extracts were filtered, lyophilized and the remnants were dissolved in DMSO and/or distilled water to prepare extract stocks of $200 \mathrm{mg} / \mathrm{mL}$. All extract stocks were sterilised by membrane filtration and stored at $-20^{\circ} \mathrm{C}$ until use.

\section{Enterococcus Samples}

Four Enterococcus samples, E. faecalis (vaginal culture isolate) (EfVCI), E. faecium (urinary catheter isolate) (EfUCI), E. faecalis NJ-3 (ATCC 51299) (EfNJ3) and E. faecium NJ-1 (EfNJ1) were used from bacterial culture collection of Ankara University, Department of Biology, Microbiology Research Laboratory.

\section{Inocula}

Before preparing the inocula, which will be used in the study, all strains were incubated at $37^{\circ} \mathrm{C}$ for 24 hours. Morphologically similar colonies were collected from Mueller Hinton Agar (MHA) by a sterile loop and the turbidity of the inocula were adjusted to $0.5 \mathrm{McFarland}$ in sterile saline solution $(0.85 \% \mathrm{NaCl})$ (Altuner and Canli, 2012).

\section{Antibiotic Susceptibility Tests}

\section{Disk Diffusion Test}

In order to determine the antibiotic susceptibility profile of the Enterococcus strains, disk diffusion method, which was previously defined by Clinical and Laboratory Standards Institute (CLSI) (2016) was used. Eleven standard antibiotic disks (Oxoid, UK), namely Kanamycin (K) $30 \mu \mathrm{g}$, Neomycin (N) $10 \mu \mathrm{g}$, Spectinomycin (SPE) 10 $\mu \mathrm{g}$, Streptomycin (STR) $10 \mu \mathrm{g}$, Ampicillin (AMP) $10 \mu \mathrm{g}$,
Nalidixic Acid (NA) $30 \mu \mathrm{g}$, Tetracycline (TE) $30 \mu \mathrm{g}$, Penicillin G (P) $10 \mathrm{U}$, Rifampicin (RD) $5 \mu \mathrm{g}$, Vancomycin (VA) $30 \mu \mathrm{g}$ and Chloramphenicol (CM) $30 \mu \mathrm{g}$ were used in antibiotic susceptibility profile test.

The MHA plates were inoculated by each inoculum, the antibiotic disks were placed on the surface of the plate in aseptic conditions and incubated at $37^{\circ} \mathrm{C}$ for 24 hours. The inhibition zones were evaluated as susceptible (S), intermediate (I) and resistant (R) according to NCCLS (Altay 1996; Handwerger et al., 1990; NCCLS 2001a; NCCLS 2001b; Tenover et al., 1993).

\section{Minimum Inhibition Concentration (MIC) Test}

The antibiotics, which was used in minimum inhibition concentration (MIC) test were selected according to the results of disk diffusion test, where antibiotics only presenting resistance in disk diffusion test were selected for MIC test. $100 \mu \mathrm{L}$ of Mueller Hinton Broth (MHB) medium was pipetted in the wells of a 96 well plate and $100 \mu \mathrm{L}$ from antibiotic stock was transferred and a 2 fold dilutions were prepared by using the first well in order to prepare a concentration range between $512 \mu \mathrm{g} / \mathrm{mL}$ and $1 \mu \mathrm{g} / \mathrm{mL} .10$ $\mu \mathrm{L}$ of inocula those were prepared according to the procedure mentioned previously was transferred into all wells. The plates were incubated at $37^{\circ} \mathrm{C}$ for 24 hours and the MIC values were identified as the minimum concentration of antibiotics inhibiting the bacterial growth. All tests were conducted in triplicates (Altuner, 2008).

All wells were analysed by a plate reader at $640 \mathrm{~nm}$ and the inhibition percentages were calculated by using the formula below.

Inhibition $\%=\left[1-\left(t_{24}-t_{0}\right) /\left(C_{24}-C_{0}\right)\right] \times 100$

Where $t_{0}$ is absorbance of the test wells before incubation, $C_{0}$ is absorbance of the negative control wells before incubation, $t_{24}$ is absorbance of the test wells at the end of the incubation period and $C_{24}$ is absorbance of the negative control wells at the end of the incubation period.

\section{Evaluating Antimicrobial Activity of Macrofungi Extracts by Agar Well Diffusion Test}

In order to use in agar well diffusion test $10 \mathrm{mg} / \mathrm{mL}$ and $50 \mathrm{mg} / \mathrm{mL}$ macrofungi extracts were prepared from 200 $\mathrm{mg} / \mathrm{mL}$ stock. After inoculation, a hole with a diameter of $9 \mathrm{~mm}$ was punched aseptically with a sterile cork borer and $100 \mu \mathrm{L}$ of extract was transferred into the wells. The plates were incubated at $37^{\circ} \mathrm{C}$ for 24 hours and the inhibition zones around the wells were recorded in mm (Silici ve Koc, 2006).

\section{Minimum Bactericidal Concentration (MBC) Test}

Minimum bactericidal concentration (MBC) test was conducted for antibiotics presenting resistance and macrofugi extracts presenting antimicrobial activity. 100 $\mu \mathrm{L}$ of suspension from all wells starting from the MIC values to the highest concentration were transferred into Eppendorf tubes and a serial dilutions (10 fold) were made by using sterile saline solution. $10 \mu \mathrm{L}$ from each Eppendorf tube was inoculated on a MHA and colonies were counted after 24 hours of incubation. A control was also observed by using wells, which didn't contain antibiotics and/or macrofungi extracts. The concentration, which causes at least a $99.9 \%(\geq 3-\log )$ reduction in bacterial load was 
defined as MBC value (Daly et al., 2017). The log reduction percentage was calculated according to the following formula.

$$
\begin{aligned}
& \log \text { reduction } \%=\left[\left(1-10^{\mathrm{LR}}\right) \times 100\right] \\
& \mathrm{LR}=\log C-\log T
\end{aligned}
$$

Where LR is $\log$ reduction, $\mathrm{T}$ is the number of colonies $(\mathrm{cfu} / \mathrm{mL})$ for the wells treated with an active substance and containing bacteria and $\mathrm{C}$ is the number of colonies $(\mathrm{cfu} / \mathrm{mL})$ for the wells only containing bacteria.

The MBC values calculated for both antibiotics and macrofungi extracts were later used in macrofungi extract/antibiotics combination studies to understand the potential interactions such as synergistic, antagonistic and additive.

\section{Determination of Biofilm Production of Enterococcus Isolates and Reference Strains}

Determination of Biofilm Production on Polystyrene Surfaces

Firstly, a range of glucose concentration $(0.0,0.25$, $0.50,1.0$ and $1.25 \%$ ) was tested in order to determine the optimum glucose concentration, which is an important nutritional component that promotes biofilm production, by the method given below. Right after determining the optimum glucose concentration, the same method was used by adding the specified concentration of glucose into culture medium for determining the anti-biofilm activities (Baldassari et al., 2001; Extremina et al., 2011).

In order to determine the biofilm production capacity crystal violet binding assay was used (O'Toole, 2011). In this assay, Enterococcus strains were incubated in Tryptic Soy Broth (TSB) for 18 hours and by using these cultures, suspensions having 0.2 optical density (OD) at $595 \mathrm{~nm}$ were prepared. $30 \mu \mathrm{L}$ of these suspensions were transferred into wells of microtiter plates as 8 replicates. The well containing only TSB medium was used as a negative control. The plates were incubated at $35^{\circ} \mathrm{C}$ for 24 and 48 hours. At the end of the incubation the wells were washed twice by sterile distilled water $\left(\mathrm{sdH}_{2} \mathrm{O}\right)$ and left to dry at room temperature. After drying process, $130 \mu \mathrm{L}$ of $1 \%$ crystal violet solution was pipetted into each well and incubated at room temperature for 30 minutes. After incubation the wells were again washed twice by $\mathrm{sdH}_{2} \mathrm{O}$ and left to dry at room temperature. $130 \mu \mathrm{L}$ of ethanol:acetone (70:30) solution was transferred into each well and incubated at room temperature for 30 minutes to dissolve crystal violet, which stained the biofilm layer. At the end of the incubation period the absorptions of crystal violet collected from each well was determined at $595 \mathrm{~nm}$ by Elisa Plate Reader (Bio-Rad, USA). Results were recorded as the mean values of 8 replicates (Vestby et al., 2009).

Determination of Biofilm Production on Stainless Steel Surfaces

In this method, AISI 304 (\#4) stainless steel coupons $(2.5 \mathrm{~cm} \times 0.8 \mathrm{~cm})$ were used to determine biofilm production capacities of Enterococcus strains. Bacterial suspensions were prepared as mentioned before (Vestby et al., 2009). The optimum glucose concentration was determined as mentioned previously and used in observing the anti-biofilm activities (Baldassari et al., 2001; Extremina et al., 2011).
In order to determine the biofilm production capacity on stainless steel coupons, $1 \mathrm{~mL}$ of bacterial suspension was transferred into test tubes containing optimum glucose concentration, TSB medium and a sterile stainless steel coupon. This procedure is conducted in two replicates. The test tubes were incubated at $35^{\circ} \mathrm{C}$ for 24 and 48 hours. At the end of the incubation, the tubes were aspirated and the coupons were washed with sterile saline solution $(0.85 \%$ $\mathrm{NaCl}$ ) to remove the bacterial cells in the planktonic form. After washing, the coupons were allowed to dry in the biosafety cabinet for 30 minutes. The dried coupons were transferred to tubes containing $4.5 \mathrm{~mL}$ sterile saline and 10 glass beads (r: $3 \mathrm{~mm}$ ) and the tubes were vortexed for 1 minute. Finally, a series of dilutions were prepared from the suspensions in the tubes and colonies were counted by drop plate inoculation to TSB agar (Giaouris et al., 2005). The colony count results were calculated at logarithmic level and the cfu in the unit area (Unit area $=\mathrm{cm}^{2}$, total surface area $=4 \mathrm{~cm}^{2}$ ) was calculated.

\section{Evaluation of the Anti-biofilm Activity of the Macrofungi Extracts}

Anti-biofilm activities of the macrofungi extracts were observed according to the methods given above. The biofilm production was determined according to the formula given below.

$$
[(\mathrm{C}-\mathrm{B})-(\mathrm{T}-\mathrm{B})] /[(\mathrm{C}-\mathrm{B})] \times 100
$$

Where $\mathrm{C}$ is the absorption of the wells containing only bacteria, $\mathrm{B}$ is the absorption of the wells containing only culture medium and $\mathrm{T}$ is the absorption of the wells containing both bacteria and macrofungi extracts. Thus, the possible anti-biofilm activities of macrofungi extracts on biofilm production, compared to the positive control group (absorbance value from wells containing only bacteria) were calculated as percentages.

\section{Determination of Biofilm Eradication Concentrations (MBEC) of Macrofungi Extracts}

In this method, stainless steel surface method and ideal biofilm production parameters were used to determine the biofilm production of Enterococcus strains. After conducting biofilm production on stainless stain coupons, they were taken from the tubes under aseptic conditions and washed to remove the cells in the planktonic phase. The washed coupons were transferred to tubes containing TSB adjusted with different concentrations $(1 \times \mathrm{MBC}$, $2 \times \mathrm{MBC}, 3 \times \mathrm{MBC}, 4 \times \mathrm{MBC}, 5 \times \mathrm{MBC}$, etc.) of macrofungi extracts. Positive control coupons (coupons not treated with macrofungus extracts) were transferred to tubes containing TSB without macrofungi extracts. The tubes were re-incubated at $35^{\circ} \mathrm{C}$ for 24 hours. At the end of incubation, the previously described method for counting biofilm cells was repeated and the reductions compared to positive control group (test tubes without macrofungus extract) were determined by logarithmic percentage reduction. The values in which the $99.9 \%$ reduction was observed were considered as MBEC values. The log reduction percentage was calculated according to the following formula given previously. 


\section{Evaluation of Antimicrobial Activities Macrofungus Extract/Antibiotic Combinations}

The possible effects of active substance combinations were evaluated based on the Chou-Talalay method, which is based on "median effect" equation derived from "mass action" principle (Chou, 2010). With this approach, the combination indices (CI) obtained according to the ChouTalalay theory allow for the quantification of possible 'additive', 'synergistic' and 'antagonistic' interactions between two or more active drug combinations $(\mathrm{CI}=1$, additive effect; $\mathrm{CI}<1$, synergism, CI $>1$, antagonism), Different combination ratios were prepared in double combination trials (macrofungus extract/antibiotic) by using stock solutions adjusted to the values above and below the EC50 concentrations, and the Compusyn software developed for this type of analysis was used to put forward the possible interactions. At least six different combinations of stock solutions were prepared and transferred to 96 well plate wells with three replicates. In order to observe the changes, in addition to the combinations, the extracts and antibiotics were used separately. Inoculum of each microorganism was used as positive control, where the culture medium was used as negative control.

Inoculation was carried out as stated previously and at the end of incubation ( 24 hours at $35^{\circ} \mathrm{C}$ ), a series of dilutions were prepared from each well. $10 \mu \mathrm{L}$ of these dilutions were transferred on TSB agar plates and colonies were counted after drop plate inoculation. The possible reductions were determined by comparing positive control groups. The dose effects of these values were calculated by means of another software (XLSTAT, Addinsoft, version 2017). After calculating the dose effects, isobologram models were determined by Compusyn software.

\section{Results and Discussion}

\section{Antibiotic Susceptibility Tests}

Disk Diffusion Test

Disk diffusion test results of isolate and reference Enterococcus strains are given in Table 1.

Disk diffusion test results were evaluated in three different groups, namely susceptible (S), intermediate (I) and resistant $(\mathrm{R})$. According to the results, it was observed that all bacteria are susceptible only against spectinomycin, which is an aminoglycoside derivative. Since all bacteria presented several inhibition zones, which were intermediate (I) and resistant (R) for rest of the antibiotics, these Enterococcus strains can be accepted to present multi-drug resistance.

Minimum Inhibition Concentration (MIC) Test

Minimum inhibition concentration test was conducted for antibiotics, which were observed to be resistant in disk diffusion test (Table 1). MIC results are given in Table 2.
Enterococci can be isolated from clinical environments as nosocomial pathogens requiring antibiotic therapy (Handwerger et al., 1992; Laverly et al., 1997). Combined treatment with $\beta$-lactam (ampicillin) or glycopeptide (kanamycin, streptomycin, neomycin) with an aminoglycoside is necessary for the treatment of severe Enterococcal infections, such as endocarditis and bacteremia, rather than urinary tract infections, which are often caused by them. However, since the rate of resistance to these antibiotics is very high, there may be serious therapeutic problems in the use of such combinations. Since Enterococci present intrinsic resistance against many antibiotics, such as penicillin and cephalosporins, treatment protocols are constantly changing (Hollenbeck and Rice, 2012).

When the resistance patterns of the nosocomial infectious pathogens especially against the first and second generation antibiotics, and the increased virulence of this resistance are taken into account, it seems logical that the clinical use preference should lead to the development of new approaches that require the combined application of natural bioactive components with common antibiotics (Kali, 2015).

The high resistance profiles of clinical Enterococcus isolates against aminoglycoside-derived antibiotics, which were used in our study, allowed us to use them in combination with the macrofungi extracts presenting antimicrobial activity.

\section{Evaluation of Antimicrobial Activity of Macrofungi Extracts \\ Agar Well Diffusion Test}

The activities of all macrofungi extracts, except the activity of $C$. squamosus on all strains and $T$. versicolor on E. faecium (urinary catheter isolate) showed an increase in the antimicrobial activity as the concentration increased (Figure 1). Figure 1 also shows that in total, L. edodes presented the highest activity among others, except 10 $\mathrm{mg} / \mathrm{mL}$ extract on EfNJ3.

Minimum Inhibition Concentration (MIC) Values for the Macrofungi Extracts

Since all extracts showed antimicrobial activity in agar well diffusion test (Table 3 and Table 4), MIC tests were performed for all extracts, which are given in Table 5. The tested concentration range for macrofungi extracts were 200, 100, 50, 25, 12.5, $6.25 \mathrm{mg} / \mathrm{mL}$. MIC values were determined at the end of 24 hours of incubation, by a spectrophotometric analysis, in which microbial growth was completely terminated (Bala et al., 2011).

According to the results, the lowest MIC concentration was determined for $M$. angusticeps and $T$. versicolor extracts.

Table 1. Disk diffusion test results $(\mathrm{mm})$

\begin{tabular}{|c|c|c|c|c|c|c|c|c|c|c|c|}
\hline \multirow{2}{*}{ Bacteria } & \multicolumn{11}{|c|}{ Antibiotics } \\
\hline & $\mathrm{P}$ & $\mathrm{K}$ & RD & VA & STR & $\mathrm{CM}$ & NA & $\mathrm{N}$ & TE & SPE & AMP \\
\hline EfVCI & $21(\mathrm{~S})$ & $10(\mathrm{R})$ & $12(\mathrm{R})$ & $15(\mathrm{I})$ & $6(\mathrm{R})$ & $11(\mathrm{R})$ & $6(\mathrm{R})$ & $18(\mathrm{~S})$ & $11(\mathrm{R})$ & $19(\mathrm{~S})$ & $31(\mathrm{~S})$ \\
\hline EfUCI & $12(\mathrm{R})$ & $6(\mathrm{R})$ & $8(\mathrm{R})$ & $22(\mathrm{~S})$ & $6(\mathrm{R})$ & 14 (I) & $6(\mathrm{R})$ & $15(\mathrm{~S})$ & $30(\mathrm{~S})$ & $20(\mathrm{~S})$ & 12 (R) \\
\hline EfNJ3 & $24(\mathrm{~S})$ & $6(\mathrm{R})$ & $21(\mathrm{~S})$ & 15 (I) & $6(\mathrm{R})$ & $9(\mathrm{R})$ & $9(\mathrm{R})$ & $8(\mathrm{R})$ & $28(\mathrm{~S})$ & $19(\mathrm{~S})$ & $32(\mathrm{~S})$ \\
\hline EfNJ1 & $6(\mathrm{R})$ & $6(\mathrm{R})$ & $15.5(\mathrm{R})$ & $6(\mathrm{R})$ & $13.5(\mathrm{I})$ & 13 (I) & $10(\mathrm{R})$ & $13.5(\mathrm{I})$ & $11(\mathrm{R})$ & $18(\mathrm{~S})$ & $30(\mathrm{~S})$ \\
\hline
\end{tabular}

Penicillin G (P), Kanamycin (K), Rifampicin (RD), Vancomycin (VA), Streptomycin (STR), Chloramphenicol (CM), Nalidixic Acid (NA), Neomycin (N), Tetracycline (TE), Spectinomycin (SPE) and Ampicillin (AMP), Susceptible (S), Intermediate (I) and Resistant (R) 
Table 2. Minimum inhibition concentration test results $(\mu \mathrm{g} / \mathrm{mL})$

\begin{tabular}{|c|c|c|c|c|c|c|c|c|c|c|c|}
\hline \multirow{2}{*}{ Bacteria } & \multicolumn{11}{|c|}{ Antibiotics } \\
\hline & $\mathrm{P}$ & $\mathrm{K}$ & $\mathrm{RD}$ & VA & STR & $\mathrm{CM}$ & NA & $\mathrm{N}$ & $\mathrm{TE}$ & SPE & AMP \\
\hline EfVCI & - & 64 & 8 & - & 256 & 128 & 128 & - & 64 & - & - \\
\hline EfUCI & 32 & 128 & 16 & - & 256 & - & 256 & - & - & - & 64 \\
\hline EfNJ3 & - & 64 & - & - & 128 & 256 & 64 & 32 & - & - & - \\
\hline EfNJ1 & 64 & 32 & 16 & 128 & - & - & 64 & - & 32 & - & - \\
\hline
\end{tabular}

Penicillin G (P), Kanamycin (K), Rifampicin (RD), Vancomycin (VA), Streptomycin (STR), Chloramphenicol (CM), Nalidixic Acid (NA), Neomycin (N), Tetracycline (TE), Spectinomycin (SPE) and Ampicillin (AMP), “-”: Not tested

Table 3. Agar well diffusion test results of macrofungi extracts $(10 \mathrm{mg} / \mathrm{mL})(\mathrm{mm})$

\begin{tabular}{l|ccccc}
\hline \multirow{2}{*}{ Bacteria } & \multicolumn{5}{|c}{ Macrofungi } \\
\cline { 2 - 6 } & M. angusticeps & G. lucidum & C. squamosus & T. versicolor & L. edodes \\
\hline EfVCI & $15 \pm 1.40$ & - & - & $20 \pm 0.28$ & $34 \pm 0.35$ \\
EfUCI & $14 \pm 0.35$ & $13 \pm 0.21$ & $17 \pm 0.35$ & $14 \pm 0.71$ & $19 \pm 1.41$ \\
EfNJ3 & $21 \pm 1.06$ & $14 \pm 0.14$ & $14.5 \pm 0.07$ & $15 \pm 0.71$ & $10 \pm 0.14$ \\
EfNJ1 & $12 \pm 0.28$ & $11 \pm 0.71$ & $18 \pm 0.21$ & $18 \pm 0.35$ & $24 \pm 0.50$ \\
\hline \hline
\end{tabular}

“-": No inhibition

Table 4. Agar well diffusion test results of macrofungi extracts $(50 \mathrm{mg} / \mathrm{mL})(\mathrm{mm})$

\begin{tabular}{l|ccccc}
\hline \multirow{2}{*}{ Bacteria } & \multicolumn{5}{c}{ Macrofungi } \\
\cline { 2 - 6 } & M. angusticeps & G. lucidum & C. squamosus & T. versicolor & L. edodes \\
\hline EfVCI & $28 \pm 1.01$ & - & - & $30 \pm 0.64$ & $40 \pm 0.50$ \\
EfUCI & $16 \pm 0.45$ & $14.5 \pm 0.36$ & $14 \pm 1.00$ & $12 \pm 0.45$ & $32 \pm 1.21$ \\
EfNJ3 & $17 \pm 0.50$ & $11.5 \pm 0.50$ & $12 \pm 0.15$ & $16 \pm 1.04$ & $18 \pm 0.82$ \\
EfNJ1 & $21 \pm 0.50$ & $13 \pm 1.08$ & $12 \pm 0.10$ & $20 \pm 0.575$ & $30 \pm 1.53$ \\
\hline
\end{tabular}

“": No inhibition

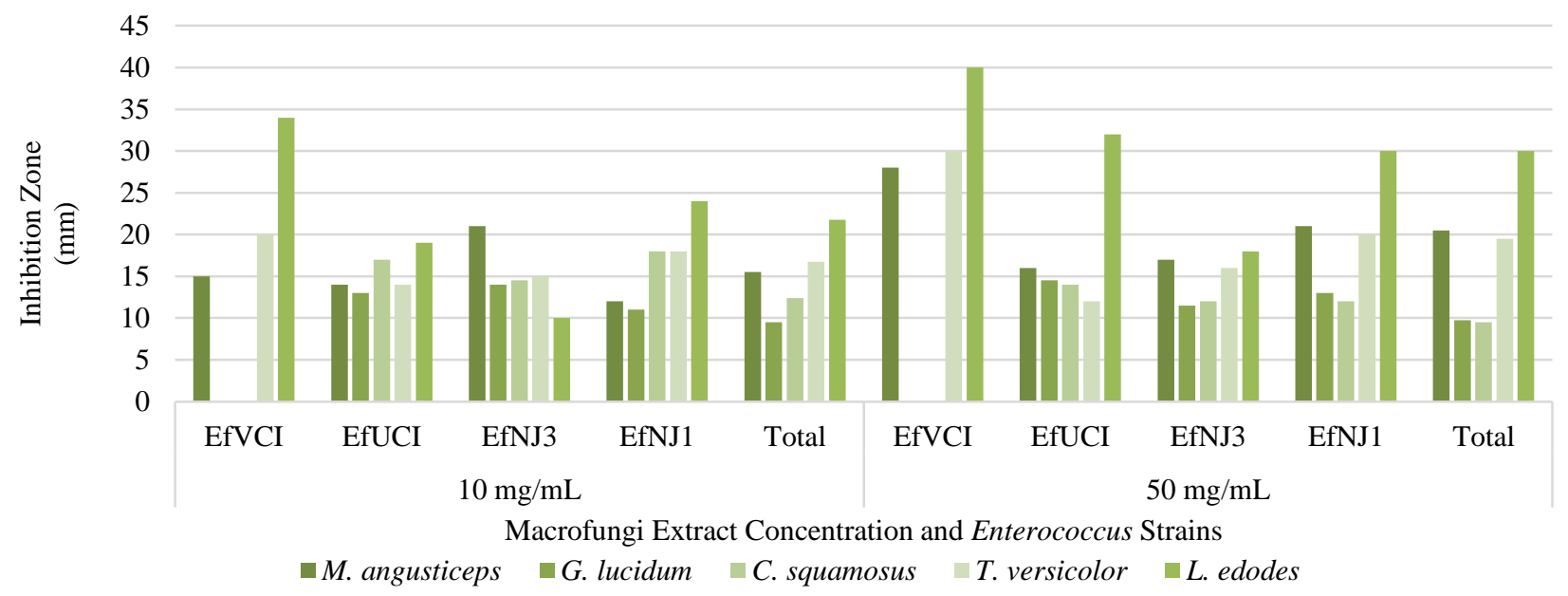

Figure 1. Comparison of the agar well diffusion test results of macrofungi extracts

\section{Calculation of MBC Values}

The MBC values were determined for both antibiotics causing resistance and macrofungi extracts presenting activity. Following the observations in MIC test and spectrophotometric analysis, a series of dilutions were prepared from the wells determined as the MIC values and higher concentrations, and from the positive control wells (without macrofungus extract) by taking $100 \mu \mathrm{L}$ suspension. After inoculating Tryptic Soy Agar (TSA) medium by drop plate method from prepared dilutions, the plates were incubated as mentioned previously.

The MBC values calculated for both antibiotics and macrofungi extracts, given in Table 6, were used in subsequent studies to detect potential synergistic, antagonistic and additive interactions in macrofungus extract/antibiotic combinations.
The reason of a fail in determining MBC values for both antibiotics and extracts may be related with two main reasons. It is most probably that bacteriostatic effects caused an obstacle to the calculation of MBC values. In addition, due to the amount of macrofungi samples the extract stock could only prepared up to $200 \mathrm{mg} / \mathrm{mL}$ concentration. Thus, it couldn't be able to test higher concentrations for extracts.

It can be concluded that G. lucidum and C. squamosus extracts showed a bacteriostatic activity against EfVCI and $E f \mathrm{NJ} 3$, where $T$. versicolor extract presented a bacteriostatic activity against EfUCI and EfNJ1 strains. Other extracts showed bactericidal activities against all strains. 


\section{Determination of Biofilm Production for Enterococcus Strains \\ Biofilm Production on Polystyrene Surfaces \\ The biofilm production conditions of Enterococcus strains were optimized in order to be able to carry out the following studies, in which macrofungi extracts will be evaluated for their anti-biofilm and biofilm eradication activities on Enterococcus biofilms. In this context, biofilm production was monitored at different glucose concentrations $(0.0,0.25,0.50,1.0$ and $1.25 \%)$ and incubation times (24 and 48 hours) at incubation temperature $\left(35^{\circ} \mathrm{C}\right)$ where the members of this genus could present maximum biofilm production. A significant increase in biofilm production was observed for all strains in incubation for 48 hours (Tukey test, $\mathrm{P}<0.05$ ) and it was determined that all strains needed different concentrations}

of glucose for an ideal biofilm production. The ideal glucose concentrations for an ideal biofilm production for EfVCI, EfUCI, EfNJ3 and Ef NJ1 were observed as $1.25 \%$, $0.50 \%, 1.25 \%$ and $0.50 \%$ respectively (Dunnett test, $\mathrm{P}<0.05$; control group = glucose-free medium) (Figure 2).

The ideal biofilm production conditions for each strain were used for all tests.

Biofilm Production on Stainless Steel Surfaces

The ideal biofilm production conditions of Enterococcus strains on stainless steel surfaces were observed to be very similar to those on the polystyrene surfaces (Dunnett test; $\mathrm{P}<0.05$ ) (Figure 3). These conditions were used in the preparation of biofilm samples of these bacteria in subsequent studies and to determine biofilm eradication concentrations (MBEC).
EfVCI

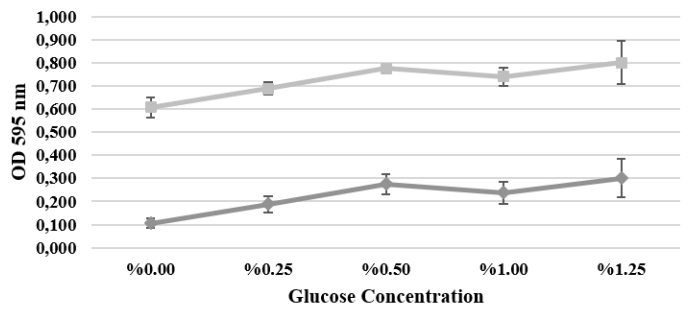

$\longrightarrow 24$ hours -48 hours

A

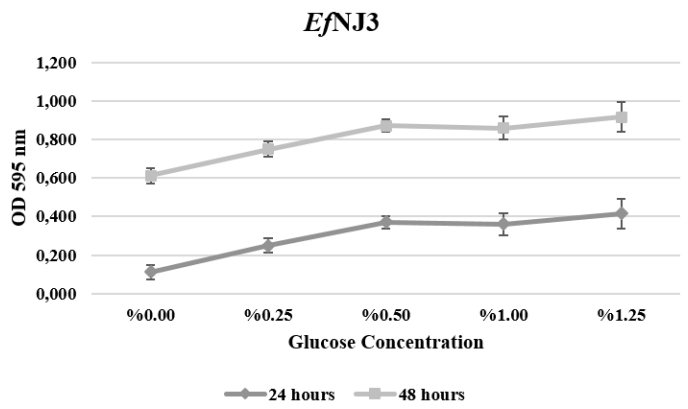

C
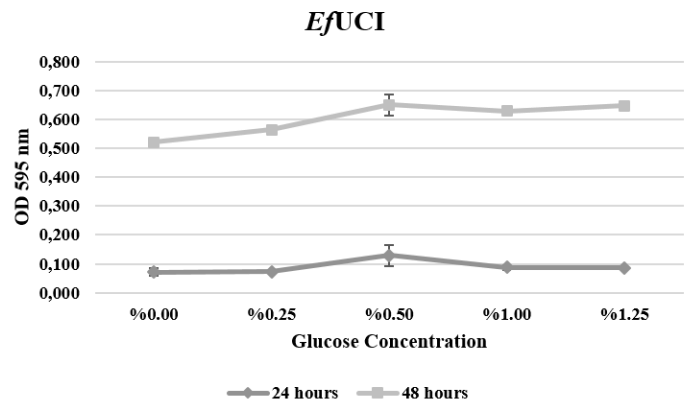

$\mathbf{B}$

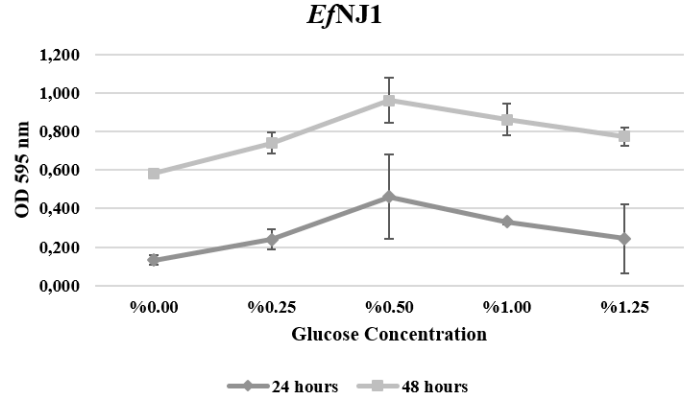

D

Figure 2. The effects of different incubation times and glucose concentrations on a) EfVCI, b) EfUCI, c) EfNJ3 and d) EfNJ1 biofilm production

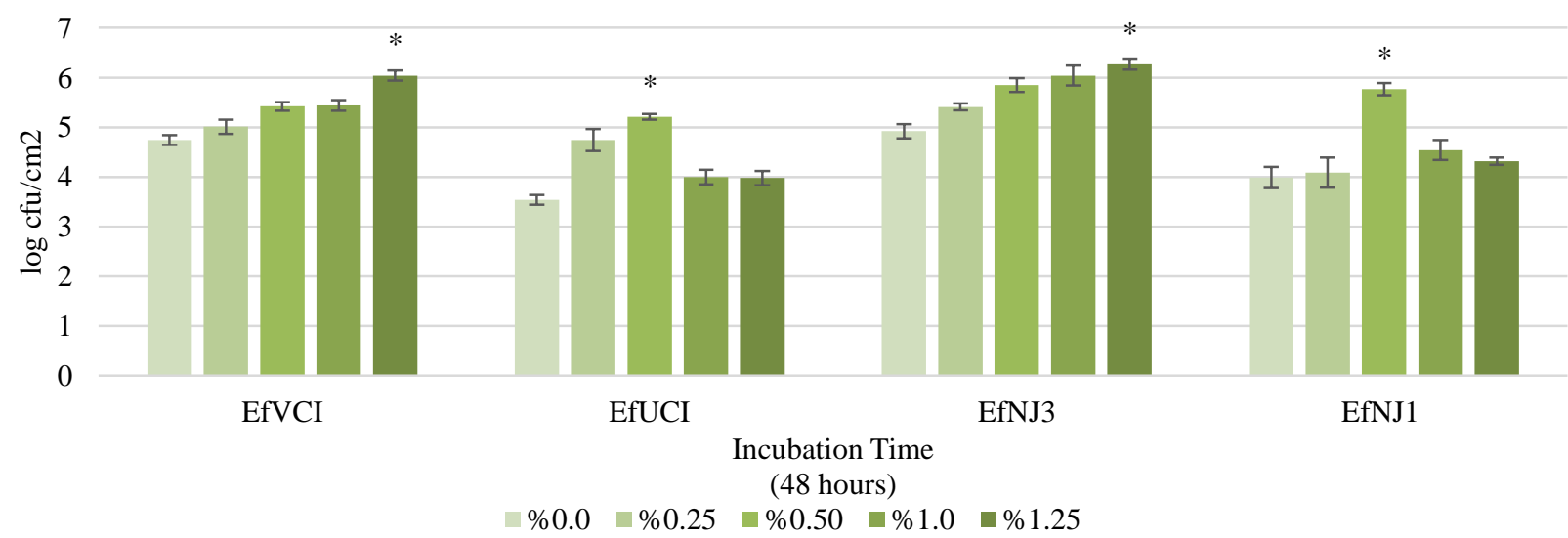

Figure 3. Biofilm production on stainless steel surfaces at different glucose concentrations of Enterococcus strains (*shows the ideal glucose concentration; Dunnett test, $\mathrm{P}<0.05$, control group = glucose-free TSB medium) 
Evaluation of the Anti-biofilm Activity of the Macrofungi Extracts

In this test a series of concentrations, namely $6.25,12.5$, $25,50,100$ and $200 \mathrm{mg} / \mathrm{mL}$ were used in order to evaluate the anti-biofilm of the macrofungi extracts. After the spectrophotometric analysis of the plates by an ELISA reader, the percentage reduction in the biofilm production was calculated from the optical density values obtained in each well and comparing them with control wells (containing no macrofungus extract). The results are given in Figure 4.

When the anti-biofilm activities of macrofungi extracts are taken into consideration, it was observed that the results obtained are in parallel with the results obtained from antimicrobial activity screening, which were given in Table 4. However, another remarkable finding within this study is; L. edodes presented anti-biofilm activity on EfNJ3 and EfNJ1 even by low extract concentrations, which weren't presented antimicrobial activity. It is evident that this extract has antimicrobial and antibiofilm activity, as well as anti-adhesive activity. The results obtained from this study are similar to the findings obtained from the studies about L. edodes in the literature. According to some previous studies the natural active ingredients of this macrofungus exhibit high anti-adhesive properties to prevent the attachment of many pathogens, especially oral pathogens, to various biotic and abiotic surfaces (Signoretto et al. 2014).

Figure 5 presents the total anti-biofilm activities of macrofungi extracts on Enterococcus strains. When the total effects of all macrofungi extracts on the biofilm production of Enterococcus strains were evaluated; the highest level of anti-biofilm activity was found to be for $M$. angusticeps and $T$. versicolor extracts, which is similar to antimicrobial activity results.

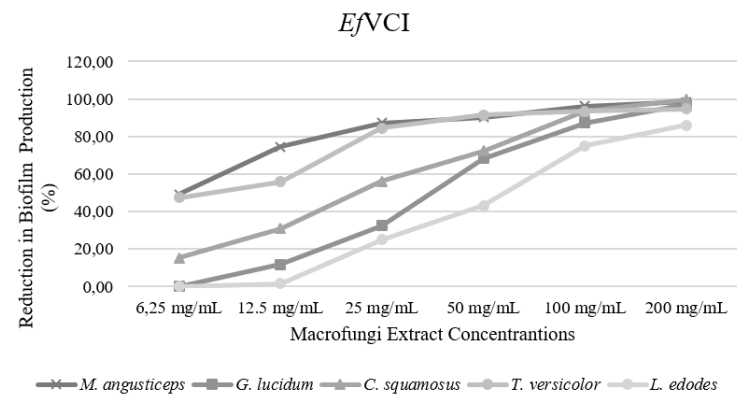

A

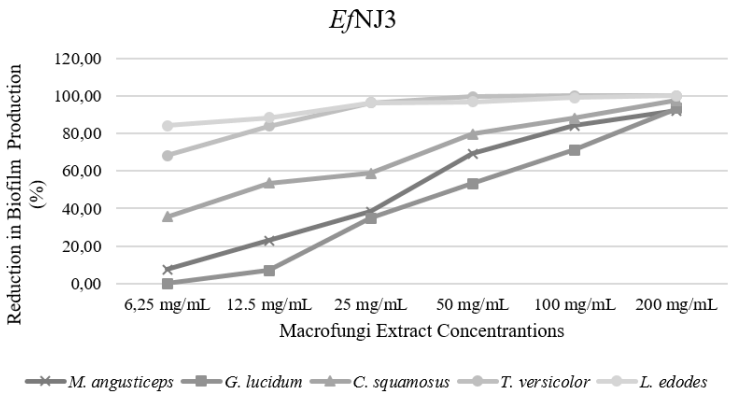

C

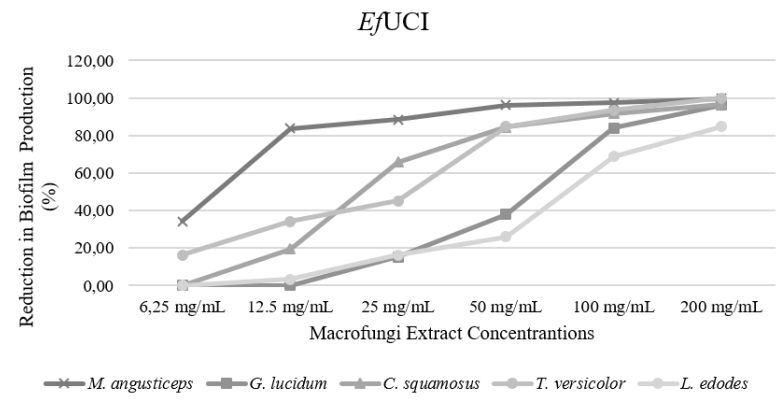

B

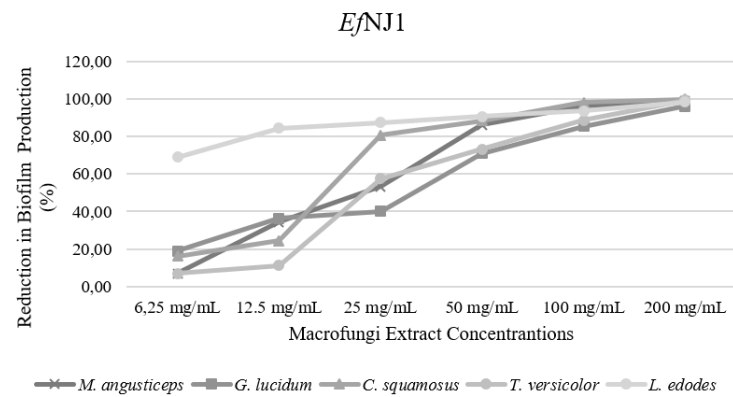

D

Figure 4. Anti-biofilm activities of macrofungi extracts on a) EfVCI, b) EfUCI, c) EfNJ3 and d) EfNJ1

Total Activity on All Enterococcus Strains

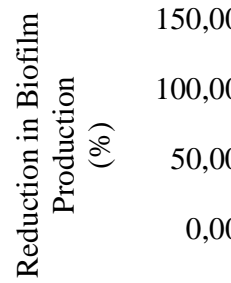

100,0

50,00

0,00

\section{$6,25 \mathrm{mg} / \mathrm{mL}$}

$12.5 \mathrm{mg} / \mathrm{mL}$

$25 \mathrm{mg} / \mathrm{mL}$

$50 \mathrm{mg} / \mathrm{mL}$

$100 \mathrm{mg} / \mathrm{mL}$

$200 \mathrm{mg} / \mathrm{mL}$

Macrofungi Extract Concentrantions

$\leftarrow$ M. angusticeps

G. lucidum

- C. squamosus

T. versicolor

L. edodes

Figure 5. Total anti-biofilm activities of macrofungi extracts on Enterococcus strains 
Table 5. MIC values for macrofungi extracts $(\mathrm{mg} / \mathrm{mL})$

\begin{tabular}{l|ccccc}
\hline \multirow{2}{*}{ Bacteria } & \multicolumn{5}{c}{ Macrofungi } \\
\cline { 2 - 6 } & M. angusticeps & G. lucidum & C. squamosus & T. versicolor & L. edodes \\
\hline EfVCI & 25 & 200 & 200 & 50 & 100 \\
EfUCI & 12.5 & 100 & 50 & 25 & 100 \\
EfNJ3 & 50 & 100 & 100 & 25 & 100 \\
EfNJ1 & 50 & 100 & 25 & 50 & 50 \\
\hline
\end{tabular}

Table 6. MBC values for both antibiotics and macrofungi extracts (mg/mL)

\begin{tabular}{l|lccl}
\hline Enterococcus Strain & Antibiotic & MBC (Antibiotic) & MBC (Extract) & \multicolumn{1}{c}{ Extract } \\
\hline \multirow{5}{*}{ EfVCI } & K & 128 & 50 & M. angusticeps \\
& RD & 16 & - & G. lucidum \\
& STR & 512 & - & C. squamosus \\
& CM & - & 100 & T. versicolor \\
& NA & 256 & 200 & L. edodes \\
& TE & - & & \\
\hline \multirow{5}{*}{ EfUCI } & K & 512 & 50 & M. angusticeps \\
& RD & 32 & 200 & G. lucidum \\
& STR & 1024 & 200 & C. squamosus \\
& NA & 512 & - & T. versicolor \\
& P & $\leq 64$ & 200 & L. edodes \\
& AMP & $\leq 128$ & & \\
\hline & K & 128 & 100 & M. angusticeps \\
& STR & 256 & - & G. lucidum \\
& CM & - & - & C. squamosus \\
& NA & 256 & 50 & T. versicolor \\
& AMP & 128 & 200 & L. edodes \\
\hline \multirow{5}{*}{ EfNJ1 } & K & 64 & 100 & M. angusticeps \\
& RD & 128 & 200 & G. lucidum \\
& NA & 256 & 100 & C. squamosus \\
& TE & 128 & - & T. versicolor \\
& $\mathrm{P}$ & 512 & 200 & L. edodes
\end{tabular}

“.": Not determined

Table 7. MBEC values for macrofungi extracts $(\mathrm{mg} / \mathrm{mL})$

\begin{tabular}{|c|c|c|c|c|}
\hline \multirow{2}{*}{ Macrofungi } & \multicolumn{2}{|c|}{$E f \mathrm{VCI}$} & \multicolumn{2}{|c|}{ EfUCI } \\
\hline & $\mathrm{MBC}$ & MBEC & $\mathrm{MBC}$ & MBEC \\
\hline M. angusticeps & 50 & $100(2 \times \mathrm{MBC})$ & 50 & $150(3 \times \mathrm{MBC})$ \\
\hline G. lucidum & - & - & 200 & - \\
\hline C. squamosus & - & - & 200 & - \\
\hline T. versicolor & 100 & $100(1 \times \mathrm{MBC})$ & - & - \\
\hline L. edodes & 200 & $200(1 \times \mathrm{MBC})$ & 200 & $200(1 \times \mathrm{MBC})$ \\
\hline \multirow{2}{*}{ Macrofungi } & \multicolumn{2}{|c|}{ EfNJ3 } & \multicolumn{2}{|c|}{ EfNJ1 } \\
\hline & MBC & MBEC & $\mathrm{MBC}$ & MBEC \\
\hline M. angusticeps & 100 & $100(1 \times \mathrm{MBC})$ & 100 & $200(2 \times \mathrm{MBC})$ \\
\hline G. lucidum & - & - & 200 & - \\
\hline C. squamosus & - & - & 100 & $200(2 \times \mathrm{MBC})$ \\
\hline T. versicolor & 50 & $100(2 \times \mathrm{MBC})$ & - & - \\
\hline L. edodes & 200 & - & 200 & - \\
\hline
\end{tabular}

"-": Exceeding maximum stock concentrations $(200 \mathrm{mg} / \mathrm{mL})$ or possible bacteriostatic effects

Determination of Biofilm Eradication Concentrations (MBEC) of Macrofungi Extracts

In this study, the MBEC values were determined by taking MBC (minimum bactericidal concentration) and above values into account. The results are given in Table 7. Considering the results obtained from the study; except for a few cases, it was observed that MBEC values are higher the MBC values.

Evaluation of Antimicrobial Activities of Macrofungus Extract / Antibiotic Combinations

EfNJ3 reference strain were used in the evaluation of antimicrobial activities of macrofungus extract/antibiotic combinations. Double-agent combinations were applied in antimicrobial susceptibility tests, where both strains were subjected to the macrofungus extract, which presented the highest sensitivity and the antibiotic, which is important in antibiotic resistance for Enterococci. A series of concentrations was prepared for the selected antibiotics and macrofungi extracts (Table 7) and EC50 concentrations were determined by counting colonies after incubation of cultures under the influence of these concentrations.

The EC50 values for both reference strains were determined by antimicrobial activity tests with antibiotic/macrofungus extract concentrations, which are given in Table 8. 
Table 8. Concentrations of Macrofungus Extract and Antibiotics

\begin{tabular}{lc|cc}
\hline \multicolumn{5}{c}{ EfNJ } \\
\hline & Antibiotics & & \\
\hline Concentration & Ampicillin & T. versicolor & Concentration \\
\hline $128 \mu \mathrm{g} / \mathrm{mL}$ & $\mathrm{X}^{*}$ & $\mathrm{X}^{*}$ & $50 \mathrm{mg} / \mathrm{mL}$ \\
$112 \mu \mathrm{g} / \mathrm{mL}$ & $\mathrm{X}$ & $\mathrm{X}$ & $40 \mathrm{mg} / \mathrm{mL}$ \\
$96 \mu \mathrm{g} / \mathrm{mL}$ & $\mathrm{X}$ & $\mathrm{X}$ & $30 \mathrm{mg} / \mathrm{mL}$ \\
$80 \mu \mathrm{g} / \mathrm{mL}$ & $\mathrm{X}$ & $\mathrm{X}$ & $20 \mathrm{mg} / \mathrm{mL}$ \\
$64 \mu \mathrm{g} / \mathrm{mL}$ & $\mathrm{X}$ & $\mathrm{X}$ & $10 \mathrm{mg} / \mathrm{mL}$ \\
$48 \mu \mathrm{g} / \mathrm{mL}$ & $\mathrm{X}$ & $\mathrm{X}$ & $5 \mathrm{mg} / \mathrm{mL}$ \\
$32 \mu \mathrm{g} / \mathrm{mL}$ & $\mathrm{X}$ & $\mathrm{X}$ & $2.5 \mathrm{mg} / \mathrm{mL}$ \\
$16 \mu \mathrm{g} / \mathrm{mL}$ & $\mathrm{X}$ & $\mathrm{X}$ & $0 \mathrm{mg} / \mathrm{mL}$ \\
$0 \mu \mathrm{g} / \mathrm{mL}$ & $\mathrm{X}$ & & \\
\hline
\end{tabular}

$\mathrm{X}$ : Concentrations of active substance (antibiotic/macrofungus extract) studied, $\mathrm{X}^{*}$ : MBC value for active substance

Table 9. EC50 concentrations

\begin{tabular}{c|c}
\hline Ampicillin & T. versicolor \\
\hline $21.2 \mu \mathrm{g} / \mathrm{mL}$ & $7.45 \mathrm{mg} / \mathrm{mL}$ \\
\hline
\end{tabular}

Table 10. The combinations used in the experimental design

\begin{tabular}{c|c}
\hline Ampicillin & T. versicolor \\
\hline 20 & 0 \\
21.2 & 0 \\
25 & 0 \\
0 & 5 \\
0 & 7.45 \\
0 & 10 \\
20 & 5 \\
21.2 & 7.45 \\
25 & 10 \\
\hline
\end{tabular}

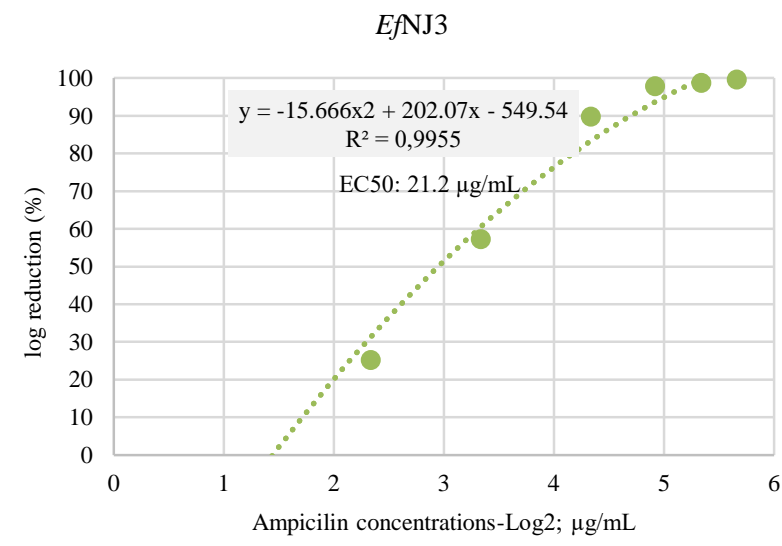

Figure 6. EC50 value and dose-response curve for Ampicillin

The colony count results obtained from the test groups (bacterial samples treated with different antibiotics and macrofungus extract) and the colony count results obtained from the positive control groups (untreated with any active substance) were compared and the logarithmic percentage (\%) reductions were calculated. Concentrations causing a $50 \%$ reduction in the bacterial population were considered as the EC50 values, which were given in Table 9. The EC50 dose-response values are the half maximal effective concentration values and are the turning point in the doseresponse curves. The EC50 values in the dose-response curves obtained in the study were determined by the "probit regression model" (XLSTAT, Addinsoft, 2017)

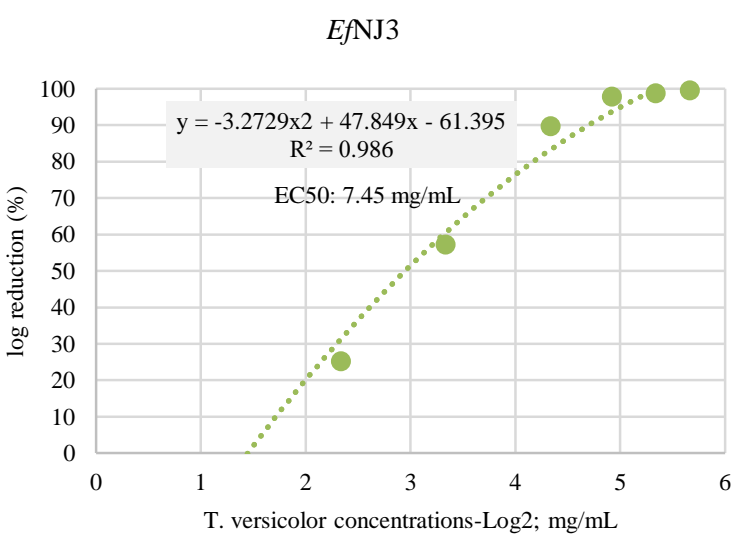

Figure 7 EC50 value and dose-response curve for T. versicolor

(Figure 6 and Figure 7). The decrease (\%) in microbial growth in different active substance concentrations was modelled by describing polynomial regression curves. Based on the slope equations, EC50 $(50 \%$ reduction in microbial growth) values were calculated by solving second degree equations (Tutorvista, calculator).

Based on the EC50 value determined, new stocks for antibiotic and macrofungus extracts were prepared those were above and below the EC50 value [(Ampicillin: 25, 21.2, $20 \mu \mathrm{g} / \mathrm{mL}),(T$. versicolor: $10,7.45,5 \mathrm{mg} / \mathrm{mL})]$. The combinations used in the experimental design are given in Table 10 . 


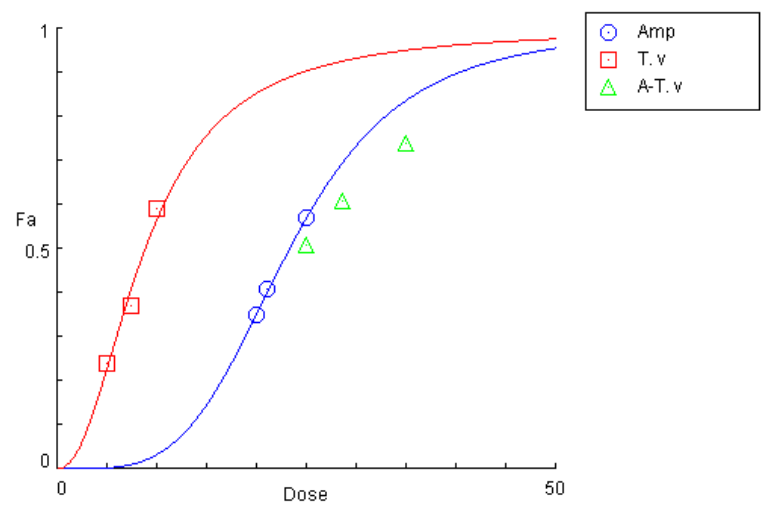

Figure 8 Ampicillin- $T$. versicolor combinations doseeffect curve for $E f \mathrm{NJ} 3$ strain

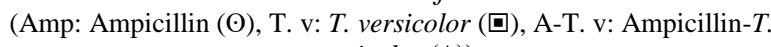
versicolor $(\Delta))$
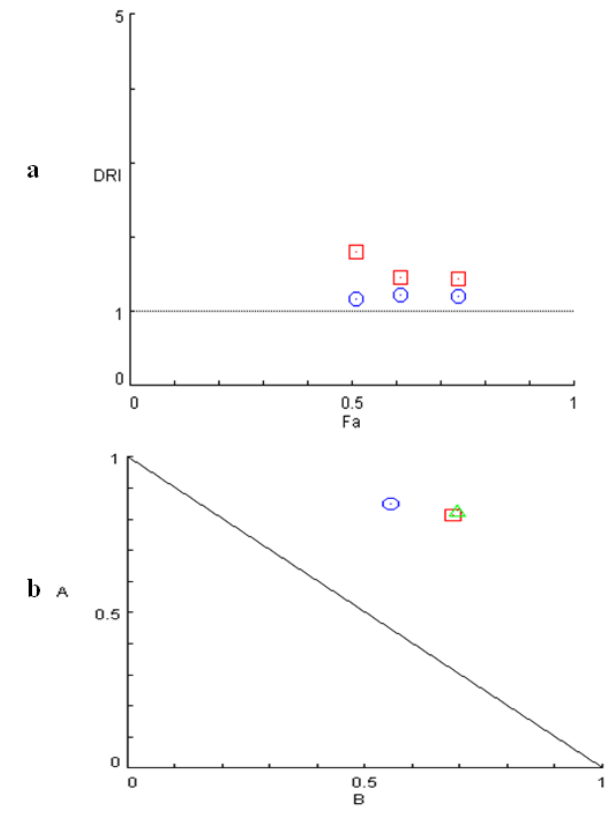

Figure 9 (DRI) Dose-response index; the values above the reference line indicate a synergetic interaction between ampicillin $(\odot)$ and $T$. versicolor $(\square)$.

Antimicrobial tests were re-performed with the combination of antibiotic/macrofungus extract concentration combinations indicated in Table 9 and individual values of each agent. The wells of microtiter plates were prepared according to concentration ratios, and after 24 hours of incubation at $35^{\circ} \mathrm{C}$, bacterial suspension samples were collected from the wells and counted. The reduction in the microbial population was calculated at the logarithmic level by comparing the count results obtained from the wells without any agent (antibiotics and/or macrofungus extract). The "dose-effects" and "dose-effect curves" were obtained according to the results for all combinations and the decreases in the population were determined by means of Compusyn software (Figure 8).

On the other hand, Figure 9 presents results for $E f \mathrm{NJ} 3$ strain, where "a" shows the dose-response index. The values above the reference line indicate a synergetic interaction between ampicillin and $T$. versicolor. Ampicillin-T. versicolor isobologram is given in " $b$ "; the distribution on the reference line again points to synergetic interaction.
As a result of this study, it was observed that the selected antibiotic-macrofungus extract interactions were synergetic in the modelling of active compound combinations. It is clear that there is high possibility to lower the doses of antibiotics to be used, with an increase in macrofungus concentrations. This modelling approach allows for the development of effective antimicrobial strategies by allowing antibiotic doses to be reduced as well as being able to be used the medicinal macrofungi species as an alternative antimicrobial for antibiotic resistance frequently found in Enterococcus strains.

Widespread and particularly misuse of antibiotics, which is one of the main reasons of the high selective pressure on nosocomial pathogens, is a factor that accelerates the spread of multiple drug resistance including Enterococcus strains (Li and Webster, 2018). The selective pressure induced by the uncontrolled antibiotics for the treatment of infections in developing countries accelerates the selection of clonal variants with multiple drug resistance (Bhattacharjee, 2016). This rapid development in antibiotic resistance leads to the ineffectiveness of many antibiotics, which are widely used, in chemotherapy (Prestinaci, 2015). The antibiotics selected in this study for evaluation of the antimicrobial tests on Enterococcus strains, such as vancomycin, are the antibiotics, which are currently in use in the treatment of infections caused by Enterococci. The resistance phenotypes that develop due to the uncontrolled use of these antibiotics lead researchers to the discovery of new natural antimicrobial compounds. The macrofungi samples, which were selected, have a high potential for such discoveries. The most important of this study is not only the evaluation of the antimicrobial and anti-biofilm activities of these macrofungi, but also the possible synergetic interactions in the case of combination use of macrofungi extracts with the antibiotics. As a result synergism was detected between the macrofungi extracts and the antibiotics, which revealed the potential for the use of antibiotics in lower concentrations. Since the macrofungi samples, which were evaluated are both edible and medically important species, the risks that may occur due to their consumption are minimal.

Today, infectious diseases are treated primarily by approaches involving antibiotic therapies together with effective antimicrobial agents; however these approaches often do not provide an effective solution in the case of biofilms of microorganisms. Considering the increased antimicrobial resistance, it is necessary to develop alternative strategies in combating infectious diseases and biofilms associated with them. Based on this need, many synthetic, semi-synthetic or natural antimicrobial agents are currently being discovered and their clinical potential is under investigation. Especially, some types of mushrooms, which have been used in traditional medicine for centuries, have important potentials for research in this direction. In the literature, many studies have been conducted to investigate the antimicrobial effects of fungal species of medical importance, on the other hand, few studies have been conducted to investigate their antibiofilm activities. Another important output of this study is proving that medical macrofungi with antimicrobial activity can also be evaluated in anti-biofilm research. 
But further research should be conducted about the antimicrobial and anti-biofilm activities especially with purified and specified active compounds of such medicinal and edible macrofungi.

\section{Acknowledgements}

The authors would like to thank to Kastamonu University, Scientific Research Projects Unit for their financial support with project number KÜBAP-01/2015-12.

\section{References}

Altay FM. 1996. Hastanede yatan hastaların dışkı kültürlerinde Enterokok kolonizasyonu ve vanomisin direncinin araştırılması. Ankara Eğitim Hastanesi (Uzmanlık tezi), s. 157.

Altuner EM, Akata I, Canl1 K. 2012b. In vitro Antimicrobial Activity Screening of Bovista nigrescens Pers. Kastamonu Üniversitesi Orman Fakültesi Dergisi. 12:90-96.

Altuner EM, Akata I, Canli K. 2012a. In vitro antimicrobial screening of Cerena unicolor (Bull.) murrill (Polyporaceae Fr. Ex Corda). Fresenius Environ. Bull. 21:3704-3710.

Altuner EM, Akata I. 2010. Antimicrobial activity of some macrofungi extracts. Sakarya Üniversitesi Fen Bilimleri Enstitüsü Dergisi. 14: 45-49.

Altuner EM, Canl K. 2012. In vitro antimicrobial screening of Hypnum andoi AJE Sm. Kastamonu Üniversitesi Orman Fakültesi Dergisi. 12:97-101.

Altuner EM, Canli K, Akata I. 2014. Antimicrobial screening of Calliergonella cuspidata, Dicranum polysetum and Hypnum cupressiforme. J. Pure Appl. Microbio. 8:539-545.

Altuner EM. 2008. Bazı karayosunu türlerinin antimikrobiyal aktivitesinin belirlenmesi. Ankara Üniversitesi Fen Bilimleri Enstitüsü Doktora Tezi, Ankara.

Bala N, Aitken EA, Fechner N, Cusack A, Steadman KJ. 2011. Evaluation of antibacterial activity of Australian basidiomycetous macrofungi using a high-throughput 96well plate assay. Pharm. Biol. 49:492-500.

Baldassarri L, Cecchini R, Bertuccini L, Ammendolia MG, Iosi F, Arciola CR, Montanaro L, Di Rosa R, Gherardi G, Dicuonzo G, Orefici G. 2001. Enterococcus spp. produces slime and survives in rat peritoneal macrophages. Med. Microbiol. Immun. 190:113-120.

Balde ES, Andolfi A, Bruyère C, Cimmino A, Lamoral-Theys D, Vurro M, Damme MV, Altomare C, Mathieu V, Kiss R, Evidente A. 2010. Investigations of fungal secondary metabolites with potential anticancer activity. J. Nat. Prod. 73:969-971.

Bentley R. 1997. Microbial secondary metabolites play important roles in medicine; prospects for discovery of new drugs. Perspect. Biol. Med. 40:364-394.

Bhattacharjee MK. 2016. Development of Resistance to Antibiotics. In: Bhattacharjee MK. Chemistry of Antibiotics and Related Drugs. USA: Springer. pp: 27-48.

Blanchette KA, Wenke JC. 2018. Current therapies in treatment and prevention of fracture wound biofilms: why a multifaceted approach is essential for resolving persistent infections. J. Bone Jt. Infect. 3:50-67.

Buommino E, Scognamiglio M, Donnarumma G, Fiorentino A, D'Abrosca B. 2014. Recent advances in natural productbased anti-biofilm approaches to control infections. MiniRev. Med. Chem. 14:1169-1182.

Canli K, Akata I, Altuner EM. 2016. In vitro antimicrobial activity screening of Xylaria hypoxylon. Afr. J. Tradit. Complement. Altern. Med. 13:42-46.

Chou TC. 2010. Drug combination studies and their synergy quantification using the Chou-Talalay method. J. Cancer Res. 70:440-446.
Clinical and Laboratory Standards Institute (CLSI). 2016. Performance Standards for Antimicrobial Susceptibility Testing. $26^{\text {th }}$ edition. USA: Clinical and Laboratory Standards Institute. ISBN 978-1-68440-032-4.

Daly SM, Sturge CR, Greenberg DE. 2017. Inhibition of bacterial growth by peptide-conjugated morpholino oligomers. In: Moulton HM and Moulton JD. Morpholino Oligomers. New York: Humana Press. pp. 115-122.

de Carvalho MP, Türck P, Abraham WR. 2015. Secondary metabolites control the associated bacterial communities of saprophytic basidiomycotina fungi. Microbes Environ. 30:196-198.

De Silva DD, Rapior S, Sudarman E, Stadler M, Xu J, Alias SA, Hyde KD. 2013. Bioactive metabolites from macrofungi: Ethnopharmacology, biological activities and chemistry. Fungal Divers. 62:1-40.

Evidente A, Kornienko A, Cimmino A, Andolfi A, Lefranc F, Mathieu V, Kiss R. 2014. Fungal metabolites with anticancer activity. Nat. Prod. Rep. 31:617-627.

Extremina CI, Costa L, Aguiar AI, Peixe L, Fonseca AP. 2011. Optimization of processing conditions for the quantification of enterococci biofilms using microtitre-plates. J. Microbiol. Methods. 84:167-173.

Giaouris E, Chorianopoulos N, Nychas GJ. 2005. Effect of temperature, $\mathrm{pH}$, and water activity on biofilm formation by Salmonella enterica Enteritidis PT4 on stainless steel surfaces as indicated by the bead vortexing method and conductance measurements. J. Food Prot. 68:2149-2154.

Hameed A, Hussain SA, Yang J, Ijaz MU, Liu Q, Suleria HA, Song Y. 2017. Antioxidants potential of the filamentous fungi (Mucor circinelloides). Nutrients. 9:1101.

Handwerger S, Perlman DC, Altarac D, McAuliffe V. 1992. Concomitant high-level vancomycin and penicillin resistance in clinical isolates of enterococci. Clin. Infect. Dis. 14:655-661.

Handwerger S, Pucci M, Kolokathis A. 1990. Vancomycin resistance is encoded on a pheromone response plasmid in Enterococcus faecium 228. Antimicrob. Agents Chemother. 34:358-360.

Hollenbeck BL, Rice LB. 2012. Intrinsic and acquired resistance mechanisms in enterococcus. Virulence. 3:421-569.

Kali A. 2015. Antibiotics and bioactive natural products in treatment of methicillin resistant Staphylococcus aureus: a brief review. Pharmacogn. Rev. 9:29-34.

Kim JE, Kim HE, Hwang JK, Lee HJ, Kwon HK, Kim BI. 2008. Antibacterial characteristics of Curcuma xanthorrhiza extract on Streptococcus mutans biofilm. J. Microbiol. 46:228.

Lavery A, Rossney AS, Morrison D, Power A, Keane CT. 1997. Incidence and detection of multi-drug-resistant enterococci in Dublin hospitals. J. Med. Microbiol. 46:150-156.

Lebeaux D, Ghigo JM, Beloin C. 2014. Biofilm-related infections: bridging the gap between clinical management and fundamental aspects of recalcitrance toward antibiotics. Microbiol. Mol. Biol. Rev. 78:510-543.

Li B, Webster TJ. 2018. Bacteria antibiotic resistance: New challenges and opportunities for implant-associated orthopedic infections. J. Orthop. Res. 36:22-32.

Losada L, Ajayi O, Frisvad JC, Yu J, Nierman WC. 2009. Effect of competition on the production and activity of secondary metabolites in Aspergillus species. Med. Mycol. 47:S88-96.

National Committee for Clinical Laboratory Standards (NCCLS). (2001a). Development of in vitro susceptibility testing criteria and quality control parameters. Approved guideline M23-A2. Wayne, PA:NCCLS.

National Committee for Clinical Laboratory Standards (NCCLS). (2001b). Performance standards for antimicrobial susceptibility testing. 11th information supplement, M100S11. Wayne, PA:NCCLS.

Ogbole O, Segun P, Akinleye T, Fasinu P. 2018. Antiprotozoal, antiviral and cytotoxic properties of the Nigerian Mushroom, Hypoxylon fuscum Pers. Fr.(Xylariaceae). Acta Pharm. Sci. 56:43-56. 
Ogidi OC, Oyetayo VO, Akinyele BJ. 2015. In vitro evaluation of antimicrobial efficacy of extracts obtained from raw and fermented wild macrofungus, Lenzites quercina. Int. J. Microbiol. Article ID 106308 .

O'Toole GA. 2011. Microtiter dish biofilm formation assay. J. Vis. Exp. 30:e2437.

Prestinaci F, Pezzotti P, Pantosti A. 2015. Antimicrobial resistance: a global multifaceted phenomenon. Pathog. Glob. Health. 109:309-318.

Roy R, Tiwari M, Donelli G, Tiwari V. 2018. Strategies for combating bacterial biofilms: A focus on anti-biofilm agents and their mechanisms of action. Virulence. 9:522-554.

Sevindik M, Rasul A, Hussain G, Anwar H, Zahoor MK, Sarfraz I, Kamran KS, Akgul H, Akata I, Selamoglu Z. 2018. Determination of anti-oxidative, anti-microbial activity and heavy metal contents of Leucoagaricus leucothites. Pak. J. Pharm. Sci. 31: 2163-2168.

Sevindik M. 2018. Antioxidant and antimicrobial activity of Cerrena unicolor. Mycopath. 16: 11-14.
Sevindik M. 2019. The novel biological tests on various extracts of Cerioporus varius. Fresenius Environ. Bull. 28: 37133717.

Signoretto C, Marchi A, Bertoncelli A, Burlacchini G, Papetti A, Pruzzo C, Zaura E, Lingström P, Ofek I, Pratten J, Spratt DA. 2014. The anti-adhesive mode of action of a purified mushroom (Lentinus edodes) extract with anticaries and antigingivitis properties in two oral bacterial pathogens. BMC Complem. Altern. M. 14:75.

Silici S, Koc AN. 2006. Comparative study of in vitro methods to analyse the antifungal activity of propolis against yeasts isolated from patients with superficial mycoses. Lett. Appl. Microbiol. 43:318-324.

Tenover FC, Tokars J, Swenson J, Paul S, Spitalny K, Jarvis W. 1993. Ability of clinical laboratories to detect antimicrobial agent-resistant enterococci. J. Clin. Microbiol. 31:1695-1699.

Vestby LK, Møretrø T, Langsrud S, Heir E, Nesse LL. 2009. Biofilm forming abilities of Salmonella are correlated with persistence in fish meal-and feed factories. BMC Vet. Res. 5:1-6. 